\title{
CRITÉRIOS DE AVALIAÇÃO DE ALUNOS: UMA CONSTRUÇÃO DOS DOCENTES DO CURSO TÉCNICO EM ENFERMAGEM DO CEPE
}

\author{
[Criteria for students' evaluation: a build-up by evangelic educational professional center's \\ teaching staff of technical nursing course] \\ [Criterios de evaluación de alumnos: una construcción de los docentes del curso técnico en \\ enfermería del CEPE]
}

\begin{abstract}
Janete M aria de Oliveira*
$M$ ariluci A Ives $M$ aftum**

$M$ arilene Lowen Wall***
\end{abstract}

RESUMO: Trata-se de um estudo com abordagem qualitativa em que cujo método utilizado foi o exploratório. Foi desenvolvido no período de agosto a dezembro de 2004, com a finali dade de construir conceitos de critérios de avaliação de al unos do curso Técnico em Enfermagem do Centro de Educação Profissional Evangélico (CEPE). Os participantes foram 10 docentes, a diretora, a coordenadora e a orientadora educacional do CEPE, totalizando 13 sujeitos. 0 desenvolvimento do trabalho ocorreu durante três oficinas, sendo que, na primeira foram definidos os conceitos que os docentes julgaram necessários a serem discutidos durante o trabalho. $\mathrm{N}$ a segunda e terceira oficina, se discutiu os conceitos: iniciativa, criatividade, responsabilidade, interação, observação, relação interpessoal e avaliação, seguidos da construção e ressignificação dos conceitos dos critérios pelos docentes. 0 presente estudo propiciou uma reflexão do que é avaliar em um Projeto Pedagógico organizado por competências, o exercício de construção de conceitos de forma coletiva e despertou nos participantes o desejo e a necessi dade de promover discussões de outros temas inerentes ao processo de avaliação.

PALAVRAS-CHAVE: Enfermagem; Ensino; Avaliação educacional.

\section{INTRODUÇÃO}

A avaliação no processo educativo tem se constituído atividade complexa para os docentes, pois carrega in-

\footnotetext{
* Enfermeira. Docente do Centro de Educação Profissional Evangélico - CEPE.

**Enfermeira. Dra docente do Departamento de Enfermagem da UFPR. M embro do Núcleo de Estudos, Pesquisa e Extensão do Cuidado Humano em Enfermagem.

***Enfermeira. Professora do Departamento de Enfermagem da Universidade Federal do Paraná, M estre em A ssistência de Enfermagem pela UFSC.
}

tenções e conotações, que dificultam o seu real reconhecimento e finalidade. Embora importante e imprescindível no planejamento educacional, a avaliação na maioria das vezes é vista somente como um instrumento de seleção e de atribuição de nota ou conceito.

Avaliar é algo que remonta a antigüidade. 0 filósofo Sócrates utilizava questões avaliativas como parte de sua metodologia de ensino, o que foi amplamente empregado na Grécia no século V a.C. No B rasil, a tendência de se ter a avaliação como sinônimo de provas e exames, é uma herança que data de 1599, introduzida pelos J esuítas que trabalhavam com a pedagogia tradicional, em que a condução de conteúdos prontos, era transmitida aos alunos, havendo a ausência de participação dos mesmos ${ }^{(1)}$.

A educação tradicional está centrada em um processo pedagógico autoritário, denominada de "educação bancária": 0 aluno adquire ou aprende conhecimentos que são transmitidos pel o professor. N essa concepção de educação a avaliação tem caráter de "medida", consiste em aferir e verificar a quantidade do conteúdo que o aluno aprendeu, cuja principal finalidade é realizar somente uma avaliação burocrática, classificatória e seletiva ${ }^{(2)}$. Entretanto, atualmente os sistemas educacionais avançam para uma avaliação menos sel etiva que possa estar integrada à ação pedagógica do dia a dia, sendo que estas mudanças vem ocorrendo a partir dos anos de 1970 e $1980^{\text {(3). }}$

No capitulo III da L ei de Diretrizes e B ases da E ducação (L.D.B ), consta que as instituições de ensino profissional devem observar na sua organização curricular, na prática educativa e na gestão da educação profissional de nível técnico: flexibilidade, interdisciplinaridade, contextual ização, identidade dos perfis profissionais, atualização permanente dos cursos e currículos, autonomia da escola e competências para laborabilidade que é a capacidade de articular os saberes (saber, saber fazer, saber ser e conviver) no mundo do trabal ho que está em constantes mudanças e desenvolvimento ${ }^{(4,5)}$. 
A partir das novas diretrizes é preciso que o docente repense a respeito dos model os pedagógicos conservadores no qual o papel do professor é o de transmitir conhecimentos enquanto que o dos al unos é o de apenas receber, sem que haja desenvolvimento crítico, pois este tipo de educação tende a conservar os valores das classes dominantes. A ssim, o projeto político pedagógico das instituições de ensino terá de ser baseado em uma tendência pedagógica transformadora com uma educação voltada para o desenvolvimento, do futuro profissional, de competências e atitudes críticas, integradas ao conhecimento técnico-científico e consciência de seus deveres e responsabilidade como cidadão diante de sua comunidade, assumindo um trabalho produtivo e a garantia que cada cidadão brasileiro receba atendimento adequado à saúde.

Conforme a L.D.B o eixo principal no ensino profissional é a construção de competências por meio da busca dos conhecimentos (teoria) e habilidades (prática) (4). Nesse sentido, o conceito de competência no contexto da educação é bastante complexo e ainda não está claro na compreensão tanto dos docentes quanto dos discentes. Esta palavra possui muitos significados o que dificul ta a utilização da mesma na prática. A competência é a capacidade que 0 aluno deverá ter de mobilizar suas aquisições escolares fora da escola em situações diversas, complexas e imprevisíveis. No senso comum competência é a capacidade de desenvolver uma atividade, mediante o domínio de materiais e conhecimentos na execução de uma tarefa (3).

$\mathrm{Na}$ organização curricular por competências 0 enfoque deve ser o de procurar desenvolver ações voltadas para aprendizagem ligadas à real idade; a construir o saber de forma coletiva relegando a competição para segundo plano e ao fortal ecimento do desenvolvimento das relações interpessoais; a articular 0 saber, o saber-fazer e o saber ser; à auxiliar o al uno a desenvolver atitude investigativa e explorar ambientes além da sala de aula ${ }^{(6)}$.

$\mathrm{Na}$ concepção pedagógica transformadora e na educação por competências, o foco deve ser voltado para que al uno desenvolva a consciência crítica e reflexiva. A ssim, a avaliação não pode desviar deste discurso, pois ela faz parte do processo educativo, devendo se constituir em uma avaliação, investigativa e abrangente, porém, sem excluir os aspectos quantitativos, pois avaliar é também valorar (nota), mas o que deve predominar é o qual itativo no processo de avaliação das competências. N este sentido, 0 objetivo principal da avaliação deve ser o de mel horar o processo de ensino aprendizagem. Ela deve possibilitar que 0 al uno cresça e desenvolva todos os seus potenciais, para isso deve permitir que o seu lado artístico e social também se desenvolva. Por conseguinte, aval iar é um meio que deve ter como fim a realimentação do processo de aprender. Contudo, chama-nos a atenção o fato de que al guns educa- dores percebem a ação de educar e a ação de avaliar como dois momentos distintos e não relacionados, porém há que se atentar que a ação de avaliar se faz presente e de forma efetiva em toda ação educativa ${ }^{(7)}$.

A avaliação deve se constituir em instrumento que propicie o crescimento contínuo, cumprindo sua função de diagnosticar, reforçar e permitir crescer. Desta forma deve ser um mecanismo motivador em que o aluno seja capaz de dominar e incorporar valores, habilidades, conhecimentos e 0 saber agi ${ }^{(1)}$. A questão não pode ser mais a nota, mas se 0 aluno aprendeu ou não. 0 uso de medida, ou seja, 0 dar nota em educação deve ser utilizado como um indicador dos erros e acertos que o professor deve utilizar para verificar o quanto de produção e de conhecimento 0 al uno atingiu, e então, a quantificação se torna um instrumento de trabal ho, se assim for compreendida. Não podemos continuar somente a "fazer provas e testes" e denominá-los como avaliação, pois, em uma analogia seria o mesmo que afirmar que o bisturi é um procedimento cirúrgico. A ssim, repensar no significado da ação avaliativa é essencial e urgente, pois quaisquer práticas inovadoras terão seu desenvolvimento comprometido se não forem alicerçadas por uma reflexão profunda a respeito de concepções de avaliação/ educação (7).

0 processo de avaliação deve auxiliar 0 aluno a aprender e a atingir as competências do planejamento de curso. Formular objetivos claros, precisos e fazer uso de critérios bem definidos para a realização da avaliação da aprendizagem é um dos grandes desafios para os docentes em todas as formas e níveis de ensino. Oferecer um ensino que visa desenvolver competências para realização da assistência de enfermagem, é um desafio complexo e difícil, porém de crucial importância, pois na assistência de enfermagem o objeto de trabal ho éo cuidado humano, isso equivale dizer que vidas com seus sentimentos, crenças e valores tanto de quem cuida como de quem recebe o cuidado, estão envolvidas.

Para que o processo de aval iação pedagógica aconteça é necessário, como já afirmamos anteriormente, que se tenha definição de critérios que irão nortear esse fazer/ essa prática, tornando mais claro para os docentes e alunos sobre exatamente o que precisa ser desenvolvido, o que ainda precisa ser trabal hado e os pontos que necessitam ser mudados e em conseqüência desta ação ter-se a avaliação não só quantitativa, mas também qualitativa. Aval iação não resolve todos os problemas educacionais, porém quando 0 professor conhece o que deve avaliar em que ocasião, porque avalia e tem definido quais os critérios que serão utilizados em seu instrumento, uma boa parte desses problemas são solucionados, um deles é conscientizar o aluno a auto-avaliar-se para que possa educar-se a si próprio ${ }^{(8)}$.

Pode-se conceber critério como o uso de princípios 
que servem de fundamento para que se possa julgar al go, e o estabelecimento de critérios é importante, pois os mesmos explicitam as "regras do jogo" o que propicia a integração entre os suj eitos envolvidos no processo de avaliação ${ }^{(9)}$. A ssim, devemos esclarecer aos alunos quais os critérios que foram estabelecidos, qual a importância dos mesmos, para que eles consigam atingir a competência da disciplina. No processo de aprendizagem os critérios podem oferecer um julgamento mais justo aos alunos, deixando claro para os sujeitos do processo ensino/aprendizagem o que é desejado, além de verificar qual foi o desempenho alcançado e oferecer reorientação precisa em caso de dificuldades.

A credito que docentes e demais profissionais envolvidos no processo pedagógico devem se apropriar dos conhecimentos concernentes a aval iação vislumbrando que ela possa se constituir instrumento útil, contributivo e eficaz no processo educativo, visando ao crescimento eà transformação do al uno ao longo do curso.

Como docente, há quase oito anos, de diversas disciplinas no curso Técnico em Enfermagem percebo que nas discussões referentes ao Projeto Político Pedagógico, quando o tema em foco é a aval iação do al uno, uma vez que se trata de assunto altamente polêmico, poucas são as conclusões a que se consegue chegar. O bservamos, entretanto que existem al guns critérios/itens de avaliação que são utilizados em todas as disciplinas e por todo o corpo docente, como por exemplo: iniciativa, criatividade, responsabilidade entre outros.

A pesar destes critérios serem comuns a todas as disciplinas do Projeto Pedagógico e estes serem utilizados por todos os docentes como parte da avaliação do aprendizado do aluno, ao recorrer a leitura de instrumentos de registros de avaliação de aluno já realizado em subfunção que 0 mesmo já cursou, percebi uma disparidade de entendimento no uso destes critérios. Constatei ainda que, alguns alunos apresentaram dificul dades em determinado critério e o mesmo persiste nas subfunções seguintes e al gumas de final de curso.

Estas reflexões nortearam o desenvolvimento deste estudo a respeito da avaliação no processo ensino aprendizagem o qual possibilitou a construção dos conceitos do grupo, relativos a alguns critérios que são comuns a todas as subfunções em que é avaliada a seguinte competência: "Avaliando a assistência dentro dos padrões éticos" do curso Técnico em Enfermagem do Centro de E ducação Profissional Evangélico, sendo eles: iniciativa, criatividade, responsabilidade, interação, observação e relação interpessoal.

Vislumbrei com este estudo encontrar caminhos, que possibilitem colaborar para tornar efetivo o projeto educacional, coerente com os princípios da Educação $\mathrm{N}$ acional. Para al cançar o intento el aborei o seguinte objetivo: cons- truir com o grupo de docentes do CEPE conceitos dos critérios de avaliação do processo ensino aprendizagem comuns a todas as subfunções do curso técnico em enfermagem.

\section{METODOLOGIA}

Trata-se de um estudo com abordagem qual itativa. A pesquisa qual itativa requer do investigador, atitudes que possi bilitem abertura, flexibilidade e capacidade de observação e integração com o grupo ${ }^{(10)}$. 0 método utilizado foi o exploratório sendo que neste tipo de estudo não se trabaIha com hipóteses, mas são elaborados objetivos, intentase fazer novas descobertas sobre o tema escol hido e vai-se familiarizando com o fenômeno, procurando maiores informações do mesmo e até descobrir novas idéias ${ }^{(11)}$.

0 projeto foi desenvolvido no Centro de Educação Profissional Evangélico (CE PE), uma instituição de ensino Profissionalizante, mantida pela Sociedade Evangélica B eneficente de Curitiba (SEB ), que oferece o Curso Técnico em E nfermagem com qual ificação deA uxiliar de Enfermagem no decorrer do curso. Participaram do estudo 10 docentes, a diretora, a coordenadora e a orientadora educacional do CEPE, totalizando 13 sujeitos. Os aspectos éticos foram considerados mediante solicitação à direção do CEPE para permissão de convidar os docentes a participar do estudo, acessar as fichas de avaliação utilizadas pela Instituição e citar o nome da Instituição no estudo e na divul gação dos resultados. 0 convite à participação dos sujeitos foi feito em uma reunião ordinária do Curso Técnico em Enfermagem, na qual foi apresentada a proposta do estudo e o seu desenvolvimento e, após os esclarecimentos, todos assinaram o termo de consentimento livre e esclarecido de acordo com a resolução n. 196 do Consel ho $\mathrm{Naci-}$ onal de saúde ${ }^{(12)}$. Os dados foram obtidos mediante estratégia de estruturação de três oficinas sendo uma oficina por mês com duração de uma hora. A s oficinas ocorreram, por sugestões da Diretora do CEPE, em uma parte do horário das reuniões ordinárias do curso Técnico em Enfermagem na própria Instituição, conforme cronograma anual.

Oficina se traduz em uma seqüência de encontros, utilizando-se de diferentes técnicas e estratégias que sejam facilitadoras e problematizadoras do tema em questão, e que auxiliem os participantes a exporem seus conhecimentos e, assim favorecer o processo de troca e crescimento geral do grupo ${ }^{(13)}$.

\section{APRESENTAÇÃO E DISCUSSÃO DOS DADOS}

Antes de realizar as oficinas reunimos dez instrumentos de avaliação que foram elaborados e também são utilizadas pelos docentes, tanto para avaliar o desempenho 
do aluno nas aulas teóricas, nas teórico-práticas supervisionadas e no estágio. Fizemos a leitura da competência em cada instrumento que contém os critérios de interesse deste estudo qual seja: "Avaliar a assistência de enfermagem dentro dos padrões éticos". Ressal tamos que esta competência está presente nos instrumentos de avaliação de todas as subfunções do currículo e nela são aval iados 15 critérios: iniciativa, interesse, criatividade, responsabilidade, relação interpessoal, pontualidade, assiduidade, sigilo profissional, postura profissional, disponibilidade, cooperação, organização, apresentação pessoal, observação e interação.

$\mathrm{Na}$ primeira oficina reafirmamos a proposta deste estudo e apresentamos a competência acima referida bem como os critérios usados para avaliar a mesma, os quais haviam sido reunidos anteriormente. Expusemos aos participantes com liberdade de sugerirem quais critérios necessitavam serem revistos. Observou-se que al guns critérios tais como pontualidade, assiduidade, apresentação pessoal e sigilo, estavam claros para os docentes, não necessitando serem discutidos. A ssim, os participantes el egeram os seguintes critérios para serem discutidos nas próximas oficinas: iniciativa, criatividade, responsabilidade, interação, observação e relação interpessoal.

$\mathrm{N}$ a segunda oficina iniciamos a discussão dos critérios selecionados na primeira. Os participantes foram divididos em seis grupos, sendo, cinco duplas e um trio, cada grupo recebeu um critério cuja tarefa foi esboçar em forma de tópicos em papel cartaz o que o docente estaria avaliando no discente quando utilizava o mesmo. A pós as el aborações, recol hemos todos os cartazes e antes de encerrar 0 encontro reafirmamos a data da próxima oficina.

Nos reunimos na última oficina elogo no início devolvemos os cartazes realizados na oficina anterior às respectivas duplas de participantes para que el es apresentassem ao grupo os critérios que haviam discutido. Na seqüência de cada apresentação abríamos espaço para sugestões, perguntas e reflexões 0 que propiciou o registro pelo pesquisador de algumas fal as que emergiram dos sujeitos, na medida em que cada critério ia sendo analisado, chegando a um consenso do seu uso e determinando a construção dos mesmos. A seguir apresentamos al guns rel atos extraídos durante este último encontro de acordo com os respectivos conceitos.

\section{Iniciativa}

"Precisamos levar em conta o momento e a especialidade para avaliar. As vezes é a primeira vez em que 0 aluno está abordando a situação".

" 0 aluno deve buscar soluções principalmente durante 0 estágio".

"Às vezes 0 aluno só vêo que foi estipulado para el e fazer. Se surge uma nova necessidade do paciente ele não realiza" . "Às vezes eles estão escalados para verificar os dados vitais e se algum paciente estiver com os dados alterados 0 aluno não faz nada e às vezes eu só consigo detectar esta necessidade do paciente no final do plantão".

Nos relatos acima é possível observar que a atitude de iniciativa do aluno quando se encontra em situações de interação e de prestação do cuidado ao paciente pode estar prejudicada devido a aspectos diversos, tais como: situações novas, dificuldades de perceber necessidades de cuidado para a qual não tenha sido alertado. Outros aspectos influentes na atitude de iniciativa pode dever-se ao medo, ansiedade, insegurança de fazer o que não Ihe foi solicitado e ser repreendido, e isto influenciar na sua avaliação. Para que 0 al uno possa ser avaliado neste conceito sem ser prejudicado pelas situações acima descritas deve-se esclarecer que se podem propor as atividades ao professor antes de executá-las então orientar e alertar 0 al uno conforme a atividade.

0 termo iniciativa é conceituado como principiar ou começar alguma ação ou fazer al guma proposta sobre algo ${ }^{\left.{ }^{14}\right)}$. Relacionando este conceito com as atividades na enfermagem percebo o quanto é importante que o profissional desenvolva esta atitude, pois o tempo de permanência dos profissionais de enfermagem com os pacientes é maior que todos os demais da equipe multiprofissional que são responsáveis pel o cuidado e o paciente mui tas vezes tem necessidades imediatas, na qual, a solução das mesmas depende da iniciativa desses profissionais.

\section{Criatividade}

" 0 aluno deve inovar respeitando os princípios básicos se assepsia".

"Q uando falta algum material 0 aluno precisa aprender a improvisar".

"Penso que criatividade é uma questão de marketing desde uma orientação até ao abordar os pacientes" .

"Ele tem que saber vender seu produto, falo de quando ele está apresentando trabalhos em sala de aula".

No item acima fica explícito que os docentes precisam incentivar, desde 0 início do curso, 0 al uno a ousar e util izar outras formas de real izar uma ação, porém sem causar prejuízo ao paciente quanto aos princípios científicos quais sejam: usar técnicas assépticas, normas e rotinas específicas de cada unidade.

Criatividade é a capacidade de gerar idéias vinculadas à original idade e adaptabilidade resul tando na solução de problemas ${ }^{(15)}$. Essa atitude deve ser estimulada já em sala durante as aulas teóricas para propiciarmos um ambi- 
ente criativo. Conquanto, se em nossa realidade, por vezes percebemos na prática de enfermagem fal ta de materiais e de recursos humanos, os pacientes, entretanto, não podem ficar sem receber o cuidado. A ssim, existe a necessidade de adaptabilidade para solução dos problemas dos pacientes.

Q uando estimulamos a execução de atividades explorando a criatividade, 0 al uno tem a oportunidade de descobrir seus talentos ao realizar os procedimentos técnicos, aprende a lidar com seus sentimentos, adquire senso de colaboração e utiliza suas energias construtivamente ${ }^{(16)}$.

\section{Responsabilidade}

"É a demonstração que está comprometida na situação". "É quando 0 aluno assume que estragou algum material ou equipamento e ele sabe que é seu dever mantê-lo em estado de uso".

"Aluno que não estuda tanto para realização das avaliações como para realizar os estágios, para mim isso é falta de responsabilidade".

N este item percebemos que na concepção dos docentes a responsabilidade se apresenta rel acionada ao quanto 0 aluno está comprometido com seu processo de aprendizagem e com o paciente, bem como, o dever que lhe cabe. A ssim, acreditamos que o profissional que está envolvido no processo de cuidar como é o trabalho em enfermagem, deve sem dúvida, estar comprometido com a sua função e estar ciente que deve responder pelas suas ações. É importante que futuro profissional de enfermagem tenha consciência dessa atitude afim de que possa desenvolver um cuidado integral.

\section{Observação}

"É quando o aluno percebe, vê e age diante das situações".

"Chega num ambiente e consegue ver em detalhes os movimentos que circundam este ambiente".

Pel os rel atos acima se evidencia que os docentes percebem a importância de desenvolver a capacidade de observar no processo cuidar, pois na enfermagem pela observação acurada se podem prevenir situações que poderiam ser prejudiciais aos pacientes e que muitas vezes se apresentam como situações de risco para suas vidas.

A observação deve ser posta em prática somente após se estabelecer uma relação com o ambiente ou pessoas que se quer observar, pois é o primeiro passo antes de qual quer ação da enfermagem. Ela é a coleta primária de dados de um ambiente ou de reações das pessoas que posteriormen- te serão interpretados. Observar é notar, prender a atenção e concentrar-se no que está ocorrendo em determinada situação (17).

\section{Interação}

" 0 aluno tem que ter flexibilidade em relação aos ambientes: fechado ou aberto..." .

"É conseguir comunicar-se com os profissionais dos diferentes setores e os pacientes".

"Não podemos esquecer que 0 aluno deve incluir os familiares neste processo".

"Penso que no primeiro estágio é muito difícil interagir, pois é o primeiro contato, assim como as primeiras atividades escolares em sala de aula".

\section{Relação I nterpessoal}

"Q uando 0 aluno demonstra um comportamento adequado".

"Tem a ver com a relação pessoa a pessoa, em que ele consegue interagir com as pessoas que estão a sua volta". " 0 aluno deve demonstrar equilíbrio emocional, sendo empático com os sujeitos que se relaciona".

Pelos relatos acima, a respei to de interagir e relacionar-se com os paciente e as demais pessoas que fazem parte do processo de trabal ho em enfermagem, para o discente iniciante é tarefa difícil, pois o mesmo se encontra em um ambiente desconhecido, falta domínio das situações e dos procedimentos. Para amenizar essas dificuldades e auxiliar no desenvolvimento dessas atitudes devemos orientá-lo acerca de dois instrumentos que poderão utilizar, a comunicação e a empatia.

Comunicar com empatia, na prática da enfermagem, é ajudar na resolução dos problemas específicos de cada pessoa sem executar ações de forma arbitrária, casual ou indiscriminada. A dquirir essa capacidade não é tarefa muito fácil, mas os profissionais de enfermagem devem se esforçar para adquirí-la, pois desta capacidade depende as ações terapêuticas que os pacientes necessitam. N este sentido, para adquirirmos essa capacidade devemos nos apropriar da observação e então poderemos conhecer qual é o estilo ou as qualidades de expressão comunicativa das outras pessoas e a partir destes dados saberemos como conduzir a comunicação com empatia e ainda se a compreensão das mensagens emitidas podem fazer grande diferença nos resultados que se pretende atingir ${ }^{(16)}$.

A comunicação é um meio pelo qual participamos do mundo que nos rodeia e nos propicia compartilhar com os outros nossas experiências. Podemos utilizar técnicas 
de comunicação como meio para atingir nossos objetivos, mas estas não levam a um fim, pois as pessoas nem sempre respondem com um comportamento ou resposta desejados ${ }^{(17) .}$

Conforme pressuposto teórico que sustenta este estudo, enfermagem éum processo interpessoal, pois está fundamentado na relação de pessoa a pessoa (17). Sendo assim, é de vital importância promover a conscientização e procurar desenvolver nos discentes desde o início de sua formação modos de comunicação para que aprendam a interagir e a relacionar-se com as pessoas. Complementando ainda, a enfermagem é a prática das relações voltada para o desenvolvimento do cuidado que utiliza um saber tecnológico construído desde Florence Nightingale ${ }^{(18)}$.

$\mathrm{Na}$ seqüência apresentamos, no Q uadro 1, a construção grupal dos conceitos dos critérios de avaliação da competência.

Quadro 1 - Critérios construídos de avaliação da competência: avaliando a assistência dentro dos padrões éticos do curso Técnico em Enfermagem do CEPE. Curitiba, 2004.

\begin{tabular}{|l|l|}
\hline CRITÉRIOS & ELEMENTOS DA AVALIAÇÃO \\
\hline Iniciativa & $\begin{array}{l}\text { Propõe atividades relacionadas aos } \\
\text { cuidados. } \\
\text { Busca de soluções no contexto } \\
\text { situacional/assistencial. } \\
\text { Demostra curiosidade nas situações de } \\
\text { aprendizagens. } \\
\text { Identifica prioridades. }\end{array}$ \\
\hline Criatvidade & $\begin{array}{l}\text { Demonstra capacidade de improvisar } \\
\text { respeitando os princípios de assepsia. } \\
\text { Apresenta idéias e sugestões de soluções. } \\
\text { Vai além da proposta sabendo incrementar. } \\
\text { Demonstra capcidade de marketing ao } \\
\text { uilizar os recursos. } \\
\text { Sai do senso comum. } \\
\text { Demonstra capacidade de abordar as } \\
\text { pessoas. }\end{array}$ \\
\hline Responsabilidade & $\begin{array}{l}\text { Assume atitudes positivas e negativas nas } \\
\text { ações/relações. } \\
\text { Compromete-se com o seu processo de } \\
\text { ensino/aprendizagem. }\end{array}$ \\
\hline Interação & $\begin{array}{l}\text { Apresenta flexibilidade quanto aos } \\
\text { ambientes e às normas e rotinas } \\
\text { institucionais. } \\
\text { Envolve-se, colabora e se comunica com o } \\
\text { grupo e a equipe multiprofissional. } \\
\text { Comunica, demosntra empatia e age } \\
\text { conforme as necessidades do paciente. } \\
\text { Informa e insere os familiares no processo } \\
\text { de cuidar. }\end{array}$ \\
\hline
\end{tabular}

\begin{tabular}{|l|l|}
\hline CRITÉRIOS & ELEMENTOS DA AVALIAÇÃO \\
\hline Observação & $\begin{array}{l}\text { Demonstra percepção das necessidades. } \\
\text { Vê e age no todo e nas partes. } \\
\text { Identifica os problemas com crítica e } \\
\text { reflexão. }\end{array}$ \\
\hline $\begin{array}{l}\text { Relacionamento } \\
\text { interpessoal }\end{array}$ & $\begin{array}{l}\text { Estabelece comunicaçãopessoa a pessoa. } \\
\text { Demosntra empatia compreendendoas } \\
\text { situações vivenciadas. } \\
\text { É receptivo às críticas com equilibrio e } \\
\text { flexibilidade. }\end{array}$ \\
$\begin{array}{l}\text { Faz uso de sigilo respeitando os valores e } \\
\text { as crenças da instituição, pacientes, grupo e } \\
\text { equipe multiprofissional. }\end{array}$ \\
\hline
\end{tabular}

Fonte: Dados da pesquisa

A ação de cuidar de vidas humanas requer dos profissionais competências bem construídas, ou seja, é preciso capacitar o al uno para mobilizar os conhecimentos, resolver os problemas dos pacientes, para isso, os responsáveis por essa formação devem deixar de utilizar a avaliação no processo de formação em saúde apenas como classificatória e terminal.

A ssim, acreditamos que, necessitamos desenvolver mais estudos nesta temática. A qui trabal hamos apenas com uma das competências avaliativas do curso, porém é 0 início de muitas transformações que precisamos fazer, a fim de que 0 ensino corresponda com uma formação voltada para 0 atendimento das necessidades de saúde da população.

\section{CONSIDERAÇÕES FINAIS}

A o iniciar este estudo a respeito da avaliação no processo ensino-aprendizagem, tínhamos a consciência de que se tratava de assunto desafiador para todos os envolvidos, mas há muito que vínhamos sentindo a necessidade de começar uma discussão e reflexão deste tema difícil e um tanto obscuro, porém inerente à ação educativa. A metodologia utilizada propiciou uma reflexão do grupo, resultando um processo dinâmico e motivador de prática profissional. A estruturação de oficinas se mostrou como oportunidade rica para estas manifestações e possibilitou envolver todos do grupo na problemática, que é o processo da avaliar, bem como, contribuiu no esclarecimento do que é real mente avaliar.

A discussão do uso de critérios foi de grande valia, pois já fazíamos uso dos mesmos, porém, cada um interpretava conforme suas experiências e seus valores, foi uma troca até chegarmos a um consenso, e acontecendo assim a 
ressignificação dos mesmos. A partir disso poderemos oferecer aos discentes uma avaliação mais justa na qual ele poderá participar do seu processo de construção do conhecimento.

N otamos que este estudo oportunizou a reflexão de todos os envolvidos no trabal ho quanto ao processo de avaliação, bem como a tomada de consciência do que é avaliar em uma proposta do processo educativo por competências. Propiciou também uma reflexão da concepção de avaliação somente como resultado, pois neste estudo criou-se um questionamento no grupo: como poderemos fazer isso? Com este questionamento podemos perceber que houve um novo significado do que é avaliar no processo educativo. Temos ainda um vasto percurso a caminhar para realizarmos uma avaliação efetiva no processo educativo, pois essa nova perspectiva exige do educador novas concepções do educando como sujeitos do seu próprio desenvolvimento dentro de sua real idade social e política. Também ter claro que todas as hipóteses, dúvidas e até mesmo os erros devem ser considerados e transformados em aprendizado. Contudo demos o primeiro passo de um caminhar que tem começo, mas não tem fim, pois esse tema é dinâmico como é todo processo da educação.

0 aluno, principalmente 0 adul to, deve ter a responsabilidade de ser o sujeito de sua própria formação e o ensino deve oferecer todos os instrumentos para o constante aprimoramento de suas capacidades cognitivas e afetivas para que possa formar profissionais com condições de interagir e criar dentro de seu contexto grandes transformações ${ }^{(19)}$.

ABSTRACT: It is a study which made use of the exploratory method with a qual itative approach. It was held from A ugust to December 2004 aiming to build up concepts of students' evaluation criteria at Evangelic Educational Professional Centre (abbreviated CEPE in Portuguese). The attendants were 10 teachers, the principal, the coordinator and the educational advisor of CEPE, taking up 13 people. The task development was carried out during three workshops; at the first one, the concepts that the teaching staff considered necessary to be discussed throughout the task process were looked over. At the second and third workshops, the concepts discussed were: initiative, creativity, responsibility, interaction, observation, interpersonal relationship and evaluation followed by builtup and reassessment of the criteria concepts by the teaching staff. This study brought about reflection on what it is to eval uate in a pedagogic project organized by competences, the team exercise of building up concepts, and it has awaken in the attendants the desire and necessity to promote discussions on topics concerning the evaluation process. KEY WORDS: Nursing; Teaching; Educational measurement.
RESUMEN: Este estudio es un proyecto asistencial de enfermaría con abordaje cual itativo cuyo método utilizado fue el de exploración. Fue desarollado en el periodo de agosto a diciembre de 2004, con la finalidad de construir conceptos de criterios de evaluación de los alumnos del curso Técnico en Enfermería del Centro de Educación Profesional Evangélico (CEPE). L os participantes fueron 10 docentes, la directora, la coordinadora y la orientadora educacional del CEPE, totalizando 13 personas. EI desarollo del trabajo ocurrió durante tres cursos, siendo que, en el primero, fueron definidos los conceptos que los docentes juzgaron necesarios discutir mientras la labor. En el segundo y tercero cursos, se discutieron los conceptos: iniciativa, creatividad, responsabilidad, interacción, observación, relación interpersonal y evaluación, seguidos de la construcción y reformulación de significados de los conceptos de los criterios por los docentes. El presente estudio propició uma reflexión de lo que es evaluar en un Proyecto Pedagógico preparado por competencias, el ejercicio de la construcción de los conceptos coletivos, y despertó en los participantes el deseo y la necesidad de promover discusiones de otros temas inherentes al proceso de evaluación.

PALABRASCLAVE: Enfermería; Enseñanza; Evaluación educacional.

\section{REFERÊNCIAS}

1. L uck G. Avaliação termômetro da educação. Rev Profissão M estre 2002; $2(12): 14-17$

2. Freire P. Pedagogia da autonomia: saberes necessários à prática educativa. 23. ed. Rio de J aneiro: Paz e Terra; 2002.

3. Perrenoud P. Avaliação da excelência à regulação das aprendizagens. Porto A legre: A rtes M édicas Sul; 1999.

4. Brasil. Lei n. 9. 394 de 20 de dezembro de 1996. Diretrizes e Bases da Educação Nacional. Disponível em: http://www.mec.gov..br/home/legislação/defaeut.shtm.(03/nov.2002).

5. B rasil. Parecer n.16/99 de 05 de outubro de 1999. Diretrizes Curriculares Nacionais para E ducação Profisssional de Nível Técnico. Diário Oficial da República Federativa do B rasil, B rasilia, 25 nov. 1999.

6. B raga R. Certificação e Currículos por Competências, Rev Linha Direta: Educação por Escrito, 2004; 9(12): 22-23.

7. Hoffmann J. Avaliação mito \& desafio. 33 ed. Porto A legre: M ediação; 2003.

8. Depresbiteris L. A valiação educacional em três atos. São Paulo: SENAC; 1999.

9. Souza CP. Avaliação do rendimento escolar. Campinas: Papirus; 1997.

10. M inayo M C. O desafio do conhecimento: pesquisa qualitativa em saúde. 6.ed. São Paulo: Hucitec/A braso, 1999. 
11. Tomasi NGS, Yamamoto RM. M etodologia da pesquisa em saúde: fundamentos essenciais. Curitiba: As autoras; 1999.

12. Brasil. Resolução n.196. Sobre pesquisas envolvendo seres humanos. Diário Oficial da República Federativa do B rasil, Brasília, 10 de out. 1996.

13. Kalinowski CE. 0 trabalho da enfermeira na rede básica de saúde: um estudo de caso.[dissertação]. Florianópolis: Setor de Ciências da Saúde da U niversidade Federal de Santa Catarina; 2000.

14. Luft CP. Dicionário da língua portuguesa 11.ed. São Paulo: Ática, 1996.

15. A rtoni C. M entes que brilham. Revista O Prazer de Conhecer Galileu, 2004; 10 (12): 38-47.

16. Daniel LF. A titudes interpessoais em enfermagem. São Paulo: EPU; 1983.

17. Travel bee J. Intervencion em enfermeria psiquiátrica. 2. ed. Cali: Organización Panamericana de la Salud; 1982.

18. Nascimento MA, M ishima SM. Enfermagem e o Cuidar. Jornal da A ssociação B rasileira de Enfermagem 2004; abr. mai. Jun.

19. Ide CA C, Dominico DLBE. Ensinando e aprendendo um novo estilo de cuidar. São Paulo: A theneu; 2001.

ENDERECO DOSAUTORES:

Rua J oão Clemente Tesseroli, 90

Curitiba-PR

81520-190

maftum@ufpr.br 